NBER WORKING PAPER SERIES

\title{
THE MEASUREMENT AND EVOLUTION OF HEALTH INEQUALITY: EVIDENCE FROM THE U.S. MEDICARE POPULATION
}

\author{
Jonathan Skinner \\ Weiping Zhou \\ Working Paper 10842 \\ http://www.nber.org/papers/w10842
NATIONAL BUREAU OF ECONOMIC RESEARCH
1050 Massachusetts Avenue
Cambridge, MA 02138
October 2004

Prepared for the Symposium in honor of Eugene Smolensky, Berkeley CA, December 12-13 2003. We are grateful to Alan Auerbach, Katherine Baicker, David Card, Victor Fuchs, Julian LeGrand, John Quigley, and seminar participants for helpful comments. Thomas Bubolz generously shared his CMHS data files and Dan Gottlieb provided critical data analysis using the Cooperative Cardiovascular Project. Financial support was provided by the National Institute on Aging Grant PO1-AG19783. The views expressed herein are those of the author(s) and not necessarily those of the National Bureau of Economic Research.

(C2004 by Jonathan Skinner and Weiping Zhou. All rights reserved. Short sections of text, not to exceed two paragraphs, may be quoted without explicit permission provided that full credit, including $\odot$ notice, is given to the source. 
The Measurement and Evolution of Health Inequality: Evidence from the U.S. Medicare Population Jonathan Skinner and Weiping Zhou

NBER Working Paper No. 10842

October 2004

JEL No. I1, I3, J7

\section{ABSTRACT}

Has U.S. health care for the elderly become more equitable during the past several decades? When inequality is measured by Medicare expenditures, the answer is yes. During 1987-2001, low income households experienced an increase of 78 percent (\$2624) in per capita expenditures, double the increase of 34 percent $(\$ 1214)$ in the highest income group. When inequality is measured by life expectancy, the answer is no. Survival for the lowest income decile grew by 0.2 years during the 1990s compared to 0.8 years in the highest income group. That the two measures deliver such discordant messages may reflect their intrinsic shortcomings; expenditures depend on preferences, health status, and prices, while outcomes are strongly affected by health behavior and past illness. We suggest a new approach to measuring inequality: the use of quality-based effective care measures. For these measures, efficacy is well proven and nearly all of the relevant population should be receiving it, regardless of health status or preferences. Using Medicare claims data matched to zip code income, we find greater use of mammography screening, diabetic eye exams, and the use of ââ blockers and reperfusion following heart attacks among higher income households, and these differences appear to be stable or growing slowly over time. In sum, the rapid relative growth in health care expenditures among low income elderly people has not translated into relative improvement either in survival or rates of effective care.

Jonathan Skinner

Department of Economics

Dartmouth College

Hanover, NH 03755

and NBER

jonathan.skinner@dartmouth.edu
Weiping Zhou

Center for Evaluative Clinical Sciences

Dartmouth Medical School

Hanover, NH 03755

weiping@dartmouth.edu 
The technological revolution in health care has brought both great benefits with respect to survival and general well-being, and substantial increases in costs. ${ }^{1}$ Whether these changes have reduced inequality in health care or in health outcomes is not well understood. Earlier research suggested that medical care innovations, such as the use of antibiotics in the treatment of tuberculosis, reduced health care disparities by race (McDermott, 1978). On the other hand, studies of health care expenditures by income group found higher income groups accounting for a larger fraction of spending, particularly after accounting for health status. ${ }^{2}$ Recent studies also suggest that better educated patients get access to newer drugs (Lleras-Muney and Lichtenberg, 2002), survive longer following the diagnosis of cancer (Glied and Lleras-Muney, 2003) and comply better with regimens for the treatment of AIDS (Goldman and Smith, 2002).

This paper returns to the question of whether technological advances and increases in health care expenditures have been associated with a widening or a narrowing of inequality in health or in health care. The group studied is the over-65 population in the United States during the 1990s, which is of interest given their high rates of utilization and very high rates of insurance coverage under the Medicare program. Initially, two conventional measures of inequality are considered: health care expenditures and health care outcomes as measured by 10 -year survival rates. Using

\footnotetext{
${ }^{1}$ Cutler et. al. (1998), Cutler and McClellan (2001), Cutler (2004), Skinner, Staiger, and Fisher (2004).

2 For the older literature, see LeGrand (1978, 1982), Le Grand et. al. (1991), Wagstaff et. al., (1991), Davis and Reynolds (1975), Link, Long, and Settle (1982). More recently see McClellan and Skinner (2004), although see Kapur et. al. (2004), and Battacharya and Lakdawalla (2004). Chen and Escarce (2004) find a pronounced negative association between income and expenditures, but reverses the association after controlling for a host of covariates measuring wellbeing and disease burden. Other studies find quite nuanced patterns, for example Gittelsohn, Halpern, and Sanchez (1991) and Morris, Sutton, and Gravelle (2003).
} 
detailed Medicare claims data on a panel of several million people in the over-65 population in the United States back to 1987, we matched individuals to income deciles based on median income in their zip code of residence. Between 1987 and 2001, we found a dramatic increase in health care expenditures among the lowest income groups, accounting for a 78 percent increase (\$2624) in real terms compared to a 34 percent increase (\$1214) for those in the top income decile. Using expenditures as a marker for health inequality, one would conclude that inequality has lessened, and if anything the higher (annual) expenditures for lower income households would help to compensate for earlier years during which insurance coverage and preventive care was minimal. ${ }^{3}$

There are a variety of disadvantages to using expenditures for health care as a measure of access, however. Expenditures may reflect patient preferences, health status, and access to care, nor is it clear how expenditures on health care translate into health outcomes (e.g., Fisher et. al., 2003a,b). For example, much of the differential increase in expenditures by income group during this period was accounted for by home health care, a program where 40 cents of every dollar in spending was deemed inappropriate by one government investigation (Havemann, 1997).

A different picture emerges in the evolution of outcomes as measured by 10 -year survival rates. While each income group experienced a survival gain during the 1990s, those in higher income groups did better: life expectancy rose by 0.2 years in the bottom income decile compares to 0.8 years in the top income decile. But this measure is not immune from criticism either. Individual decisions regarding healthy behavior exert an important influence on health outcomes over the life-course, and it is rarely clear whether these choices should be attributed to "preferences," education, or economic status per se

\footnotetext{
${ }^{3}$ See Decker, 2004; McWilliams, et. al., 2003; Card, Dobkin, and Maestas, 2004.
} 
(Graham, 2002; Contoyannis and Jones, 2004; Smith, 2003). As well, long and variable lags in outcomes make it difficult to evaluate the impact of the current health care expenditures on changes in current health outcomes, particularly when income itself is endogenous to health status (Case and Deaton, 2003).

That the two measures of health inequality are contradictory suggest the need for a different approach. We propose focusing on a more limited set of effective (or highquality) utilization measures with well-established benefits. ${ }^{4}$ These measures include mammography screening among women age 65-69, eye examinations for diabetics, and smoking cessation advice, aspirin, $\beta$-blockers, and reperfusion in the first 12 hours following the heart attack. These latter three treatments accounted for the vast majority of improvement in 30-day survival following heart attacks (Heidenreich and McClellan, 2001). The advantage of these measures over expenditures is that one need not control for health status; nearly everyone in the appropriate universe should be receiving these treatments. Nor does one need to control for preferences towards health care, or for lifestyle differences; every appropriate heart attack patient should be receiving $\beta$ Blockers upon admission, regardless of whether they are marathon runners or couch potatoes. ${ }^{5}$ The use of these measures are not dependent on genetic or environmental factors that might further confound differences in survival rates across income groups. As well, there is increasing effort to collect these measures as components of health care quality indices, for example by the National Committee for Quality Assurance (NCQA) at the hospital level or by Jencks (2003) at the state level.

\footnotetext{
${ }^{4}$ This terminology follows that in Wennberg et. al. (2002).

${ }^{5}$ In some cases, preferences can still play a role in screening programs, see Walter et. al. (2004). The question is then raised as to whether those preferences against effective care reflect past adverse encounters with the health care system.
} 
Using the Medicare claims data augmented with the Cooperative Cardiovascular Project (CCP) data for heart attack patients in 1994/95, we find distinct income gradients with regard to the use of effective care. For mammography, examination rates for the top income decile were 16 percentage points higher than the lowest decile in 1993, and by 2001 the gap had shrunk only slightly to 15 percentage points. For the inpatient treatment of heart attacks in 1994/95, where the use of effective care is unlikely to have any incremental impact on patient costs and where noncompliance is minimal, the income gradients are smaller; 7 percentage points for $\beta$ blockers and 5 percentage points for reperfusion therapy within 12 hours, with no significant differences in aspirin or ACE inhibitor use. ${ }^{6}$

In sum, the dramatic increases in relative Medicare expenditures for low income neighborhoods during the past several decades have not translated into similar improvements in health outcomes. The apparent lack of relative improvement in effective care among the lowest income groups makes this puzzle less surprising, but by itself cannot explain the widening of survival trends by income group. ${ }^{7}$ Still, the use of effective care measures can allow the government to work towards actually doing something about inequality in health care. Monitoring and rewarding providers and patients to raise rates near the 100 percent ideal for all Medicare enrollees would have the additional salutary effect of erasing inequality in the dimension of effective care.

\footnotetext{
${ }^{6}$ Reperfusion therapy (12-hour surgical angioplasty or "clot busting" thrombolytics) is effective at removing the blockage or clots restricting blood flow to the heart. Aspirin is effective at breaking down platelets that are essential components of these clots interfering with blood flow. ACE inhibitors attenuate the body's natural tendency to constrict vascular walls, while $\beta$ blockers reduce the body's demands on the heart.

${ }^{7}$ See also Baicker and Chandra (2004), who have shown this lack of association between Medicare expenditures and effective care measures at the regional level.
} 


\section{The Measurement of Health and Health Care Inequality}

It is important to distinguish between inequality in health care and inequality in health. There is a long history of measuring inequality in health care by the use of utilization or expenditures measures. Le Grand $(1978,1982)$ and others found a positive gradient between expenditures and income after controlling for measures of health status in the United Kingdom, even after several decades of National Health Insurance. While there was a lively debate about how best to measure income-based gradients in health care ( Wagstaff et. al., 1991, Le Grand, 1991), the positive association between expenditures and income has been found in many countries with just a few exceptions (Wagstaff et. al., 1991). The earlier evidence from the United States pointed towards the same positive association between expenditures and income (Davis and Reynolds, 1975; Link, Long, and Settle, 1982), although more recent data on Medicare expenditures in the 1990s suggests that lower income households have began to account for higher levels of spending (Lee, McClellan, and Skinner, 1999; McClellan and Skinner, 2004.

Health care expenditures have been used to construct measures of "full income" that include both money income and government-financed health care expenditures. This approach was pioneered by Eugene Smolensky and his colleagues at Wisconsin during the 1970s in the study of income distribution (Reynolds and Smolensky, 1977; Moon, 1977), and extended to valuing health care benefits in a money-metric context (Smolensky, et. al., 1977). More recently, Fuchs (1998a, 2001) has used this approach to document the very large fraction of full income among the elderly in the U.S. comprised of health care expenditures, most of which is paid for by younger generations. The implicit message in creating full income measures is the opportunity cost of health care 
spending, that a reduction in health care spending could have a large impact on money income, particularly among low income groups.

The interest in illness-adjusted expenditures or utilization can be motivated by a concern about access to care, where the null hypothesis of perfect equality is presumably one where high income and low income individuals with similar medical ailments would be treated with the same procedures and with the same degree of intensity. But some have questioned whether equal rates of utilization are really the same as equal access, for example if people with high incomes experienced different preferences for care (Mooney et. al., 1991, Culyer et. al., 1992). While economists are generally comfortable taking preferences as given, the issue is less clear in the health care literature. For example, Ibrahim, et. al. $(2001,2002)$ documented more distrust of surgery among black candidates for hip or knee replacement, and placed greater reliance on alternative (nonsurgical) approaches such as copper bracelets or prayer. Katz (2001) has distinguished between preferences "guided by informed decisions" and those "limited by truncated opportunities or historical circumstances." Thus if low income households are less likely to seek care because of past adverse encounters with the health care system, their choices today may be related less to immutable preferences and more to past financial or cultural barriers in access to care.

Another shortcoming of using health expenditures is that higher levels of expenditures may not translate into better health outcomes. Glover (1938) counseled against the overuse of tonsillectomies at a time when the risk of surgical complications was high. He and his colleagues noted that children of anxious high-income parents were more likely to receive the procedure and hence more likely exposed to the risk of 
operative mortality. More generally, Fisher et. al. (2003a, b) has suggested that regions with greater use of health care were no more likely to experience better outcomes or even improved satisfaction of patients and access to care. In other words, higher expenditures do not always translate into better health.

In the past decade, there has been an increasing interest in the inequality of health, whether measured as lifespan, quality-adjusted life years, healthy life years, or selfreported health. ${ }^{8}$ Measuring health outcomes avoids the problem of inferring the effectiveness of health care expenditures on outcomes. It also has the advantage of capturing income-based differences in a variety of factors such as health behavior, diet, and life-course events that have a larger impact on health outcomes than the health care system alone. The results are if anything quite a bit stronger, exhibiting a uniform and consistent gradient between income and health care outcomes.

Inequality in health outcomes can be present even in the absence of inequality in health care. Suppose that the health care system were perfectly equal, and provided instant access to all people in society. Inequality in outcomes could still occur for a variety of reasons. The first is simply luck or genetic differences across the population (Gakidou, Murray, and Frenk, 2000). However, most summary measures of incomebased health inequality remove this source of inequality by averaging over large numbers of individuals. For example the "concentration index" compares the cumulative distribution of income on the horizontal axis, and the cumulative distribution of healthy

\footnotetext{
${ }^{8}$ Berloffa, Brugiavini, and Rizzi, 2003; Case and Deaton, 2003; Contoyannis and Jones, 2004; Elstad and Krokstad, 2003; Gakidou, Murray, and Frenk, 2000; Glied and Lleras-Muney, 2003; Goldman and Smith, 2002; Preston and Taubman, 1994; Van Doorslaer, et. al., 1997; Wagstaff and van Doorslaer, 2004.
} 
life years (however measured) on the vertical axis, thereby averaging out variation occurring within income categories. ${ }^{9}$

The second source of lifespan inequality arises from potential differences in health behavior such as diet, smoking, exercise, drinking, and other factors associated with income and socioeconomic status, so that “... inequalities in health reflect the wider inequalities in society." (Le Grand, 1982, p. 45.) For example, Contoyannis and Jones (2004) report that these measures of "healthy living" in 1984 were strong predictors of positive good health in 1991. Of course, this raises the very difficult question again of how one can separate "preferences" for health-related behavior from income per se. These health behaviors or health shocks can have long-lasting effects, for example see Almond's (2003) study of the long-term negative repercussions of being in utero during the 1918 influenza epidemic. As well, these long-term health shocks can affect both earnings capacity and health, muddying the causal link between income and health outcomes even further (Case and Deaton, 2003; Elstad and Krokstad, 2003; Graham, 2002).

We suggest a more restrictive but theoretically cleaner measure of health care inequality: to measure utilization rates of effective care, procedures that are efficacious for every appropriate patient. Examples include mammography screening for women aged 65-69, and $\beta$ blocker, aspirin, reperfusion therapies, and ACE inhibitor use for heart attack patients. ${ }^{10}$ Mammography has been adopted as a measure of preventive care in

\footnotetext{
9 The measure of inequality is then calculated much like the Gini coefficient; for a general discussion of health inequality decompositions, see Contoyannis and Forster (1999).

${ }^{10}$ Reperfusion therapy (12-hour angioplasty or "clot busting" thrombolytics) is effective at removing the blockage or clots restricting blood flow to the heart. Aspirin is effective at breaking down platelets that are essential components of these clots interfering with blood flow. ACE
} 
other studies as well, for example see Decker (2004) and Card, Dobkin, and Maestas (2004).

There are several advantages in using such measures. The first is the existence of a reliable link between utilization and health outcomes. Second, there is no need to control (however imperfectly) for health status, since among appropriate or ideal patients, nearly everyone should receive the treatment. Finally, preferences should generally not play a strong role in the use of such interventions, given that the objective benefits are so much larger than the costs. ${ }^{11}$ Trends or levels in several of these effective care measures will be considered further below, after first examining the empirical record on the evolution of health care expenditures and survival by income group.

\section{The Distribution of Medicare Expenditures by Zip Code Income}

The Continuous Medicare History Survey (CMHS), a 5 percent sample of every Medicare enrollee, is used to consider the secular trends of overall Medicare expenditures by income decile. Because individual income is not available in the Medicare claims data, we instead use median zip code income from the 1990 U.S. Census, assigned to each individual in the Medicare denominator file based on their mailing address zip code. (The results are not sensitive to the use of the 2000 Census income data.) There are advantages and disadvantages of using zip code income from the Census instead of individual income data from surveys. On the one hand, the neighborhood that a person

inhibitors attenuate the body's natural tendency to constrict vascular walls, while $\beta$ blockers reduce the body's demands on the heart.

${ }^{11}$ In practice, Walter et. al. (2004) has pointed out that preferences could play a legitimate role for some patients who may not want to be screened. These arguments are harder to make in the case of heart attack treatments; it seems unlikely that anyone should prefer not to take aspirin following a heart attack. Alternatively, one may view the benefits as being sufficiently high to justify paternalistic efforts on the part of the government to encourage such practices. 
lives in may better reflect permanent income than self-reported income, which may be infested with measurement error and transitory income, and particularly for the elderly population not reflect important components of household wealth. On the other hand, zip code income is subject to "ecological bias," poor Medicare enrollees in rich neighborhoods could be treated differently from rich enrollees in poor neighborhoods. One previous study, however, has suggested that zip code income provides a reasonable characterization in health-related research (Geronimus, et. al., 1996).

In quantifying health care expenditures for the over 65 population, we express all expenditures in 2001 dollars, and estimate age-sex-specific expenditures in 5-year age increments (plus those $85+$ ) for each of 10 income deciles. In aggregated data, we use direct adjustment to normalize the per capital Medicare expenditures to a constant age and sex composition over time by use of the sample frequencies of the 10 age-sex categories. ${ }^{12}$ Only fee-for-service Medicare enrollees are included in the sample, which means that expenditures made on behalf of enrollees in Medicare managed care will not be included in this sample. ${ }^{13}$ The sample size is sufficiently large (30.8 million personyears) that standard errors are small, and so are not reported.

Table 1 and Figure 1 present expenditures for selected income deciles in 19872001. Not surprisingly, real Medicare expenditures have increased during this period.

12 Thus the age-sex frequencies are averages over 1987-2001. Just the $80+$ population is considered in quantifying home health care, and so for this group there are four age-sex categories, males 80-84, males 85+, females 80-84, and females $85+$.

${ }^{13}$ Until 1997, managed care organizations were reimbursed for their Medicare enrollees by a capitated fee based on $95 \%$ of the lagged value of regional fee-for-service expenditures, so that fee-for-service expenditures within a region would have been a reasonable measure of the managed care capitation fee. While the Balanced Budget Act of 1997 severed that close link, it is not expected that the relatively small fraction of Medicare managed care enrollees would bias these results. 
However, the rates of growth by income group are quite different; the bottom decile experienced a 78 percent increase in real expenditures, in contrast to the top decile with just a 34 percent increase.

The advantage of health care dollar expenditures is that these changes in spending can be compared to changes over the same period of time in median money income, as measured in the Current Population Survey. The median increase in family income during the period 1987-2001 was $\$ 2551 .^{14}$ In 1993, the average household size of elderly people living either along or with a spouse was $1.47,{ }^{15}$ so the per capita increase in income per elderly person was $\$ 1735=\$ 2551 / 1.47$. Note that the dollar increase in expenditures for the lowest income decile was $\$ 2624$, compared to $\$ 1214$ for the highest income group. Thus the size of the differential increase (or "twist") in Medicare expenditures was $\$ 1410$ (\$2624 minus $\$ 1214$ ) or the amount of money that would have been left "on the table" had Medicare costs for the lowest income group grown at the same rate as the highest income group. This differential increase is therefore 81 percent of the total increase in money income for the elderly population during 1987-2001. It is also larger than the average level of per capita benefits from the Earned Income Tax Credit (EITC) program, estimated to be $\$ 1287$ (in 2001 dollars) among the near-poor (Short and Garner, 2002). Unlike the EITC, the redistribution occurring in the Medicare

${ }^{14}$ In 2001 dollars, http://www.census.gov/hhes/income/histinc/f11.html.

${ }^{15}$ U.S. Census (1996) Page 6.6. To estimate the average household size, we excluded people 65+ living with other relatives or with unrelated people, and assumed the spouse was also age $65+$. 
program was largely unintended, and the differential benefits to the lowest income group are still not well understood. ${ }^{16}$

Why the differential growth in expenditures? One reason was the growth in the Disproportionate Share Hospitals (DSH) program that provided higher reimbursements for hospitals in low income neighborhoods (see Baicker and Staiger, 2004). Another factor was the rapid expansion of home health care during the 1990s. Beginning in the late 1980s, when restrictions on the use of home health care were eased, there were dramatic increases in the use of home health care particularly in certain regions of the U.S. such as Texas, Florida, and Tennessee (Wennberg and Cooper, 1999). Because of the rapid growth in expenditures, and an accompanying increase in scandals, Congress restricted its use sharply in 1997. These expenditures for home health care were concentrated to a large extent in the poorest zip codes of the U.S. ${ }^{17}$ Figure 2 tabulates average home health care spending for the $80+$ population (the most common users of home health care) by year for the lowest income Decile 1, Deciles 5, and the highest income Decile 10. These are measures of spending per Medicare enrollee age 80 and older, and not restricted just to users of home health care. There was rapid growth in home health care expenditures for all income groups, but the growth for Decile 1 was

\footnotetext{
${ }^{16}$ One shortcoming with these changes in Medicare expenditures is that we do not have similar data on Medicaid expenditures. In theory, a decline in Medicaid expenditures among the low income groups could have been offset by this sharp increase in Medicare expenditures, with no net impact on transfers to lower income neighborhoods. However, Medicaid expenditure data by state and by year for home health care expenditures provides little support for this explanation. While Medicaid programs in New York were spending more on recipients than in Texas in 1991 (\$623 versus \$74), by 1997 the spending levels had not changed appreciably (\$647 in New York, \$146 in Texas). Source: http://www.cms.hhs.gov/statistics/nhe/state-estimatesresidence/medicaid-per-capita50.asp

17 See Lee, McClellan, and Skinner (1999).
} 
particularly notable, rising to $\$ 1635$ per elderly enrollee before dropping after 1997 when the Balanced Budget Act clamped down on unrestricted use.

How much of this spending benefited low income patients, either through improved survival or improved quality of life? In 1997, a report by the General Accounting Office suggested that $40 \%$ of all home health care costs were "inappropriate" (Havemann, 1997). In this case, inappropriate care included either fraud (e.g., a physician prescribing tests for sexually transmitted diseases to all of his home health care patients) or that the patient simply was not eligible for home health care. A recent paper by Robin McKnight (2004) did not find adverse health consequences caused by the sharp decline in home health care benefits in 1997, although there was a modest consequent increase in out-of-pocket medical expenses. In short, one should be cautious about attributing all dollar increases in Medicare expenditures to the people who nominally "receive" the benefit. ${ }^{18}$ Home health care is not the only service provided during the 1990 s that may have also benefited providers' bank accounts, but it was certainly the most visible. ${ }^{19}$

\section{The Distribution of Survival Gains by Income}

We next consider overall survival gains in the Medicare population. Here the sample includes not just the fee-for-service population but also the HMO enrollees; this is to avoid potential selection bias caused by healthier individuals joining managed care

${ }^{18}$ This is the basic insight of tax incidence studies, the tax burden does not necessarily fall on the people who pay the tax. Similarly, government benefits do not necessarily flow to the people whose names are on the checks.

19 Another cause for the rapid increase in health care expenditures during the 1990s was upcoding whereby hospitals switched patients from low-reimbursement to high-reimbursement diagnostic related groups (Silverman and Skinner, 2004) and effectively increased the price charged per Diagnostic-Related Group (DRG). Upcoding, which is distinguishable from "bracket creep" by the absence of supporting evidence for the more expensive coding, was curtailed sharply also around 1997 following well-publicized investigations of a large for-profit hospital chain. 
organizations. We consider two different cohorts from the Continuous Medicare History Survey. The first is the group of people age 65-69 and 75-79 alive in 1982, and the second is the corresponding group alive at age 1992. Figure 3 shows the percentage of the groups age 65-69 in the initial year who were still alive ten years later by sex and year of the cohort by income decile. There is a clear income gradient in both years; people living in higher zip code incomes were more likely to survive during both the 1980 s and 1990s. A similar pattern is shown for those aged 75-79 in 1982 and 1992, detailed in Table 2, with life expectancy rising by more for men than for women. While all groups gained in terms of survival probabilities, the highest income groups gained the most, both in percentage and in absolute terms.

To quantify these changes in terms of the change in expected survival years, we chain together the two panels of 10 year survival curves for the younger and older cohorts, and estimate the change in expected survival years for a synthetic cohort over a 20 year period (from 65-69 to 85-89) with fixed weights for men and women based on the fraction of women in the age $65-69$ cohort (54.8 percent). There was a 0.2 increase in expected life years in the bottom income decile, a 0.5 increase in the 5 th decile, and a 0.8 increase in the top income decile. ${ }^{20}$

\section{Inequality in the Provision of Effective Care}

Here we focus on specific measures of effective care, considering first mammography rates among women age 65-69 in the Medicare population. The advantage of using

\footnotetext{
${ }^{20}$ Recent work has focused on placing a dollar value to increased survival, see Becker, Philipson, and Soares (2003) or Berloffa, Brugiavini, and Rizzi (2003). A different approach to quantifying the changes over time in survival is the concentration index, a variant of a Gini coefficient (Contoyannis and Forster, 1999). However, changes in the index were very small since we were just considering inequality in the over 65 population and not over the entire life-course.
} 
mammography rates is that we have a time-series on rates of screening from 1993-2001 and so can measure changes over time in screening rates. A 5\% sample of Part B physician claims data is used from 1993-1997, and a 20\% sample from 1998-2001. The later $20 \%$ sample also includes hospital outpatient data as separate from physician-based claims, these would include women who were screened for example in a hospital-based clinic. In theory, not including such outpatient records for all years could bias our results if low income women were more likely to receive care in an outpatient setting. In practice, as we show using data from 1998-2001, the bias is small or non-existent.

Figure 4 shows rates of screening by year for selected income deciles for just the physician claims, these are comparable over time. Reported in brackets during 19982001 are rates that include the outpatient screening data; while raising all rates the relative magnitudes by income group are largely unchanged.

There is a pronounced income gradient in screening rates that persists throughout the period of analysis. In 1993, the range in screening rates (between Decile 1 and Decile 10) was 16 percentage points, while in 2001, the range had shrunk slightly to 15 percentage points. A notable feature of the data is the sharp jump in rates between 1997 and 1998. This was the consequence of removing the $\$ 100$ coinsurance payment on January 1, 1998 and allowing reimbursement for annual rather than biannual screening. It is surprising that rates for all income groups appear to have risen by about the same amount, given that low income households should have been most sensitive to the relaxation of the $\$ 100$ copayment.

Similar results for 1998-2001 were also found in comparing rates of screening for eye examinations among patients with diabetics. These examinations check for damage 
to the vascular system caused by high uncontrolled blood glucose levels (available upon request from the authors). While encompassing a shorter time period, there was similarly no evidence of trends in the income-based gradient of screening for diabetic eye examinations.

Of course, some part of the income-based differential could be the consequence of noncompliance; that is that lower income patients don't sign up or show up for their screening appointment. We therefore consider physician directives or procedures performed in the first few days following acute myocardial infarction, where the primary goal of the physician is to keep the patient alive, and patient preferences and noncompliance issues should play a small role. The measures of effective care for heart attack patients are derived from the Cooperative Cardiovascular Project (CCP) survey of more than 160,000 AMI patients over age 65 in 1994/95. The survey information included detailed clinical data from chart reviews along with information on how the patient was treated. This allowed clinical researchers to determine from the chart data patients who were "ideal" or appropriate for the use of the specific treatment; thus the right rate should be a number near 100 percent, regardless of health status, income, age, or any other characteristic. For this reason, we do not control for covariates or health indices, but consider simple averages by income decile.

Table 4 presents income-based differences in utilization of effective care along with the total sample size in the bottom row. Approximate $95 \%$ confidence intervals are presented at the bottom of the table; these apply to each of the means in the column because the deciles ensure equal sample sizes and the exact binomial confidence intervals are based on the average ratio. 
Table 4 suggests that in 1994/95, utilization of these measures were remarkably low. For example, the use of $\beta$ Blockers was less than half of appropriate patients when the target rates should have been closer to 100 percent. Second, rates of use for effective care were modestly elevated among higher income groups; for example in $\beta$ Blockers, rates ranged from 40 percent in the bottom income decile to 47 percent in the top decile. Indeed, for some treatments, such as ACE inhibitors used to control hypertension, there were no income-based difference in utilization.

One additional question is whether high income individuals are more likely to receive higher quality care because of treatment differences within regions, or because they are more likely to live in regions where overall effective care rates are higher (Chandra and Skinner, 2003). In Figure 5 utilization rates for $\beta$ Blockers are estimated with and without categorical regional variables. First, the previous results are replicated in a logistics regression coefficients converted to percentage screening rates. State dummy variables are then introduced and the logistics regression is re-estimated, again with odds ratios converted to probabilities, and shown in Figure 5. The adjusted probability of $\beta$ Blocker use holding constant the state of residence shows just a 3.6 percentage point difference by income group rather than a 7 percentage point difference. (In this latter regression, only the $8^{\text {th }}$ and $10^{\text {th }}$ decile coefficients were significantly different from zero.) That is, half of the income gradient here is the consequence of where patients live and not how patients are treated within regions. The result does not generalize, however. A similar analysis for mammography screening and diabetic eye 
exams during 1998-2001 did not suggest any diminution in the effects of income on utilization rates after controlling for region of residence. $^{21}$

In theory, we would like to know how the income gradient in $\beta$ Blocker use evolved over time, but we have just one observation from the survey in 1994/95. Since the use of $\beta$ Blockers for heart attack patients were rare before the early 1980s, we may safely infer that the observed difference in 1994/95 reflects a somewhat higher growth rate in the use of $\beta$ Blockers among the top income deciles, at least through 1994/95. Since then, compliance has improved, but in 2001 median compliance is still less than 70 percent (Jencks, 2003). It is possible that rates of compliance have risen more rapidly in low income regions, but Alabama was low in the use of $\beta$ Blockers in 1994/95 and it remained relatively low in 2001 .

\section{Conclusions and Discussion}

How should one judge whether inequality in health has improved or worsened during the past several decades? This paper has considered several alternative approaches to measuring inequality using US data from the elderly Medicare population over age 65. While Medicare expenditures grew much more rapidly among the lowest income deciles, health outcomes improved much less rapidly for this group. Economists and health services researchers have long recognized the distinction between inequality in health care (as measured by expenditures) and inequality in health (as measured by survival), beginning at least with Victor Fuchs' comparison of Nevada and Utah, two

\footnotetext{
${ }^{21}$ In this case, because the sample sizes were so much larger, we were able to use the 306 hospital referral regions (Wennberg and Cooper, 1999) as regional controls instead of states as in the analysis of $\beta$ blockers.
} 
states with similar health care expenditures but very different mortality rates (Fuchs, 1998b).

We suggest a different approach to measuring inequality that relies on effective care, or measures of health care quality. For these measures, efficacy is well proven and nearly all of the relevant population should be receiving it, regardless of health status or preferences. A examination of the past decade suggests that there has been little or no relative improvement in the utilization of effective care measures among lower income deciles. Thus the discordance between rapidly rising health expenditures of low income households and rapidly rising longevity of high income households is not quite so puzzling.

It should be cautioned that the magnitudes of the differences in effective care observed in the data would not be expected to exert a large impact on overall mortality rates. The predicted impact on heart attack patients of a 7 percentage point increase in $\beta$ blocker use (i.e., the difference between the top and bottom income decile rate of use) is a 0.21 percentage point decline in mortality, or an overall impact on the general population of about 0.01 percent since just 5 percent of the Medicare population experience a heart attack in any year. ${ }^{22}$ The fact that these measures of effective care account for a small fraction of overall expenditures, and a small fraction of the overall variation in health outcomes, motivates interest in other measures of quality, for example with regard to the overuse of marginally effective procedures (Fisher, et. al., 2003a,b).

22 The 0.21 percent shift is derived by multiplying 7 percentage points times the implied 3 percentage point reduction in one-year mortality estimated by using an odds ratio (estimated for 30 day mortality) of 0.88 reported in Heidenrich and McClellan (2001). 
There are three important limitation of this study. The first is that in using outcome data, we have focused only on survival and not quality-adjusted or "healthy life years." To capture a more full measure of health, it would be necessary to include income-based differentials in treatments with proven effectiveness but for improving functioning rather than survival per se. Examples include hip or knee replacements for the treatment of osteoarthritis or the use of angioplasty for patients with ischemic heart disease. However, measuring true income-based differences in health status is more difficult, given the necessity of adjusting for differential health needs (i.e., rates of osteoarthritis of the hip by income group) and for preferences (however defined) regarding surgical intervention. ${ }^{23}$

Second, the study is limited to just the over-65 population. Focusing just on income-based differences in mammography rates within the Medicare program ignores the fact that Medicare itself contributes to a substantial increase in mammography rates at age 65 among those previously uncovered by insurance or in lower educational groups (Decker, 2004; Card, Dobkin, and Maestas, 2004). Focusing just on inequality within a specific age group ignores changes in inequality across age groups, for example differences between those under age 65 who are increasingly lacking health insurance, and those over age 65 who are generally covered (Danziger, Haveman, and Smolensky, 1977).

Finally, we have not considered the financing side of the Medicare program. During the 1990s payments both rose and became more progressive as general income taxes became a larger source of revenue (McClellan and Skinner, 2004). The new

${ }^{23}$ Chen and Escarce (2004) for example attempt to control for income-based differences in health status along a wide variety of dimensions. 
prescription drug benefits passed into law in 2003 should also contribute to an increasing degree of redistribution to the extent the future growth in benefits are financed out of general tax revenue. Whether increased progressivity in the Medicare program would justify the increased longevity of higher income households is not entirely clear, however.

A singular advantage of focusing on equality in effective care (or quality of care) is that there are reasonable approaches to fixing the problem. Monitoring claims data in real time with the objective of raising rates to ideal levels of near $100 \%$ among appropriate candidates is one sure way to at least reduce income-based inequality in health outcomes. Inequality in outcomes would continue to persist for many years, of course, but at least such differences would not be exacerbated by inequality in health care. Indeed, one could imagine "non-discrimination" rules like those developed for 401(k) pension plans in which hospitals or health care systems would experience a partial loss in Medicare funding if effective care measures for their low income patients fell too far below those for their high income patients. 


\section{References}

Almond, Douglas, "“"Is the 1918 Influenza Pandemic Over? Long-term Effects of In Utero Influenza Exposure in the Post-1940 U.S. Population" mimeo, National Bureau of Economic Research, 2003.

Auerbach, Alan, Jagadeesh Gokhale, and Laurence J. Kotlikoff, "Social Security and Medicare Policy from the Perspective of Generational Accounting," in J.M. Poterba (ed.) Tax Policy and the Economy 6. Cambridge: NBER and MIT Press (1992).

Baicker, Katherine, and Amitabh Chandra, "Medicare Spending, the Physician Workforce, and Beneficiaries' Quality of Care” Health Affairs (April 7, 2004).

Katherine Baicker and Douglas Staiger, "Fiscal Shenanigans, Targeted Federal Health Care Funds, and Patient Mortality," Quarterly Journal of Economics (forthcoming, 2004).

Battacharya, Jay, and Darius Lakdawalla, "Does Medicare Benefit the Poor? New Answers to an Old Question," NBER Working Paper No. 9215 (revised, 2004).

Becker, Gary S., Thomas J. Philipson, and Rodrigo R. Soares, "The Quantity and Quality of Life and the Evolution of World Inequality," NBER Working Paper No. 97645 (June 2003).

Berloffa, Gabriella, Agar Brugiavini, and Dino Rizzi, "Health, Income and Inequality: Evidence from a Survey of Older Italians," University of Venice Working Paper (January 2003).

Bommier, A., and G. Stecklov, "Defining Health Inequality: Why Rawls Succeeds Where Social Welfare Theory Fails," Journal of Health Economics 21(3) (2002): 497514.

Card, David, Carlos Dobkin, Nicole Maestas, "The Impact of Nearly Universal Insurance Coverage on Health Care Utilization and Health: Evidence from Medicare," NBER Working Paper No. 10365 (March 2004).

Case, Anne, and Angus Deaton, "Broken Down By Work and Sex: How Our Health Declines," NBER Working Paper No. 9821 (July 2003).

Chandra, Amitabh, and Jonathan Skinner, "Geography and Racial Disparities in Health," NBER Working Paper (February 2003).

Chen, Alex Y., and José Escarce, "Quantifying Income-Related Inequality in Healthcare Delivery in the United States," Medical Care 42(1) (January 2004): 38-47. 
Contoyannis, Paul, and Martin Forster, "The Distribution of Health and Income: A Theoretical Framework," Journal of Health Economics 18(5) (1999): 605-622.

Contoyannis, Paul, and Andrew M. Jones, "Socio-Economic Status, Health, and Lifestyle," Journal of Health Economics (2004, forthcoming).

Culyer, A.J., Eddy van Doorslaer, and Adam Wagstaff, "Comment: Utilisation as a measure of equity by Mooney, Hall, Donaldson, and Gerard," Journal of Health Economics 11 (1992): 93-98.

Cutler, David M. and Mark McClellan, "Is Technological Change in Medicine Worth It?" Health Affairs (Sept/Oct 2001): 11-29.

Cutler, David M., Your Money or Your Life: Strong Medicine for America's Health Care System. New York: Oxford University Press (2004).

Cutler, David, Mark McClellan, Joseph Newhouse, and Dahlia Remler, "Pricing Heart Attack Treatments," Quarterly Journal of Economics 113(4) (November 1998), 991-1024.

Danziger, Sheldon, Robert Haveman, and Eugene Smolensky, "The Measurement and Trend of Inequality: Comment," American Economic Review 67(3) (June 1977): 505-512.

Davis, Karen, and Roger Reynolds, "Medicare and the Utilization of Health Care Services by the Elderly," Journal of Human Resources 10(3): 361-77 (1975).

Deaton, Angus, and Christina Paxson, "Mortality, Income, and Income Inequality Over Time in Britain and the United States," NBER Working Paper No. 8534 (October 2001).

Decker, Sandra, "Medicare and the Health of Women with Breast Cancer," mimeo, 2004.

Elstad, Jon Ivar, and Steinar Krokstad, "Social Causation, Health-Selective Mobility, and the Reproduction of Socioeconomic Health Inequalities Over Time: Panel Study of Adult Men," Social Science and Medicine 57 (2003): 1475-1489.

Fisher, Elliott S., David Wennberg, Therese Stukel, Daniel Gottlieb, F.L. Lucas, and Etoile L. Pinder, "The Implications of Regional Variations in Medicare Spending. Part 1: The Content, Quality, and Accessibility of Care," Annals of Internal Medicine 138(4) (February 18, 2003a): 283-287.

Fisher, Elliott S., David Wennberg, Therese Stukel, Daniel Gottlieb, F.L. Lucas, and Etoile L. Pinder, "The Implications of Regional Variations in Medicare Spending. Part 2: Health Outcomes and Satisfaction With Care" Annals of Internal Medicine 138(4) (February 18, 2003b): 288-299. 
Fuchs, Victor, "Provide, Provide: The Economics of Aging" NBER Working Paper No. 6642 (July 1998a).

Fuchs, Victor, Who Shall Live? Health, Economics, and Social Choice. World Scientific Publishing (1998b).

Fuchs, Victor, “The Financial Problems of the Elderly: A Holistic Approach," NBER Working Paper No. 8236 (April 2001).

Gakidou, E.E., C.J.L. Murray, and J. Frenk, "Defining and Measuring Health Inequality: An Approach Based on the Distribution of Health Expectancy," Bulletin of the World Health Organization 78(1) (2000): 42-54.

Geronimus, Arline, John Bound, and Lisa Neidert, "On the Validity of Using Census Geocode Characteristics to Proxy Individual Socioeconomic Characteristics," Journal of the American Statistical Association 91(434): 529-537 (1996).

Gittelsohn, Alan M., Jane Halpern, and Ricardo L. Sanchez, "Income, Race, and Surgery in Maryland," American Journal of Public Health 81(11) (November 1991): 143541.

Glied, Sherry, and Adriana Lleras-Muney, "Health Inequality, Education, and Medical Innovation,” NBER Working Paper No. 9738 (May 2003).

Glover, J. A., "The Incidence of Tonsillectomy in School Children," Proceedings of the Royal Society of Medicine 31 (1938): 1219-1236.

Goldman, D.P and J.P. Smith. 2002. "Can Patient Self-Management Help Explain the SES Health Gradient?" Proceeding of the National Academy of Sciences of the United States of America 99(16): 10929-10934.

Gornick, Marian E., Paul Eggers, Thomas Reilly, Renee Mentnech, Leslye Fitterman, Lawrence Kucken, and Bruce Vladeck, "Effects of Race and Income on Mortality and Use of Services Among Medicare Beneficiaries," New England Journal of Medicine 335: 791-799 (1996).

Graham, Heather, "Building an Inter-Disciplinary Science of Health Inequalities: The Example of Lifecourse Research," Social Science and Medicine 55 (2002): 2052016.

Havemann, Judith, "Fraud is Rife in Home Care for the Elderly; Medicare Investigators Find 40\% of Services Unjustified," The Washington Post (July 29, 1997) p. A01.

Heidenreich, Paul A., and Mark McClellan, "Trends in Treatment and Outcome for Acute Myocardial Infarction: 1975-1995," American Journal of Medicine 110 (2001): 165-74. 
Ibrahim, S.A., L.A. Siminoff, C.J. Burant, and C.K. Kwoh, "Variations in Perceptions of Treatment and Self-care Practices in the Elderly with Osteoarthritis: A Comparison Between African American and white Patients," Arthritis and Rheumatism 45 (2001): 340-45.

Ibrahim, S.A., L.A. Siminoff, C.J. Burant, and C.K. Kwoh, "Understanding Ethnic Differences in the Utilization of Joint Replacement for Osteoarthritis," Medical Care 40 (Suppl 1) (2002): I44 - I55.

Jencks, Stephen F., Edwin D. Huff, and Timothy Cuerdon, "Change in the Quality of Care Delivered to Medicare Beneficiaries," JAMA 289(3) (January 15, 2003), 305-312.

Kapur, Kanika, Jeanette A. Rogowski, Vicki A. Freedman, et. al., "Socioeconomic Status and Managed Care Expenditures in Medicare Managed Care," NBER Working Paper No. 10757 (September 2004).

Katz, Jeffrey N., "Patient Preferences and Health Disparities," JAMA 286 (2001): 1506-9

Le Grand, Julian, "The Distribution of Public Expenditure: The Case of Health Care," Economica 45(178) (May 1978): 125-142.

Le Grand, Julian, The Strategy of Equality. London, George Allen \& Unwin (1982).

Le Grand, Julian, "The Distribution of Health Care Revisited: A Commentary on Wagstaff, van Doorslaer and Paci, and O'Donnell and Propper," Journal of Health Economics 10 (1991): 239-245.

Lee, Julie, Mark McClellan, and Jonathan Skinner, "The Distributional Effects of Medicare Expenditures," in J. Poterba (ed.) Tax Policy and the Economy 13 (1999)

Link, Charles R., Stephen H. Long, and Russell F. Settle, "Equity and the Utilization of Health Care Services by the Medicare Elderly," Journal of Human Resources 17(2) (1982): 195-212.

Lleras-Muney, Adriana, and Frank R. Lichtenberg, "The Effect of Education on Medical Technology Adoption: Are the More Educated More Likely to Use New Drugs?" NBER Working Paper No. 9185 (September 2002).

Lubitz, James, and Gerald Riley, 1993, "Trends in Medicare Payments in the Last Year of Life," New England Journal of Medicine 331: 1092-1096.

McClellan, Mark, and Jonathan Skinner, "The Incidence of Medicare." Mimeo, Dartmouth College (2004). 
McDermott, W. "The Public Good and One's Own." Perspectives in Biology and Medicine 21 (1978): 167-188.

McKnight, Robin, "Home Health Care Reimbursement, Long-Term Care Utilization, and Health Outcomes," NBER Working Paper No. 10414 (April 2004).

McWilliams, J.M,. Zaslavsky A.M., Meara E., Ayanian J.Z., "Impact of Medicare coverage on basic clinical services for previously uninsured adults," New England Journal of Medicine 290 (2003): 757-764.

Moon, Marilyn, "The Economic Welfare of the Aged and Income Security Programs," in M. Moon and E. Smolensky (eds.) Improving Measures of Economic Well-Being. New York: Academic Press (1977).

Mooney, Gavin, Jane Hall, Cam Donaldson, and Karen Gerard, "Utilisation as a Measure of Equity: Weighing Heat?” Journal of Health Economics 10 (1991): 475-480.

Morris, Stephen, Matthew Sutton, and Hugh Gravelle, "Inequity and Inequality in the Use of Health Care in England: An Empirical Investigation," Center for Health Economics Technical Paper No. 27, The University of York (December 2003).

Pappas, G., et al., "The Increasing Disparity in Mortality Between Socioeconomic Groups in the United States," New England Journal of Medicine 329: 103-109 (1993).

Preston, Samuel, and Paul Taubman, "Socioeconomic Differences in Adult Mortality and Health Status," in Linda G. Martin and Samuel Preston (eds.) Demography of Aging (Washington DC: National Research Council and the National Academy Press) (1994).

Reynolds, M., and E. Smolensky, Public Expenditures, Taxes, and the Distribution of Income: The U.S., 1950, 1961, 1970. (New York: Academic Press, 1977).

Ross, Christine M., Sheldon Danziger, and Eugene Smolensky, "Interpreting Changes in the Economic Status of the Elderly, 1949-79," Contemporary Policy Issues 5 (April 1987): 98-112.

Sassi, F., L. Archard, and J. Le Grand, "Equity and the Economic Evaluation of Healthcare." Health Technology Assessments 5(3) (2001): 1-130.

Skinner, Jonathan, and Douglas Staiger, "The Diffusion of Technology: From Hybrid Corn to Beta Blockers," Mimeo, Dartmouth College (May 2004).

Skinner, Jonathan, Douglas Staiger, and Elliott Fisher, "Is Technological Change in Health Care Always Worth It? The Case of Acute Myocardial Infarction," mimeo, Dartmouth Medical School (October 2004). 
Short, Kathleen, and Thesia I. Garner, "Experimental Poverty Measures Under Alternative Treatments of Medical Out-of-Pocket Expenditures: An Application of the Consumer Expenditures Survey." U.S Census (May 28, 2002).

Silverman, Elaine, and Jonathan Skinner, "Hospital Ownership and Medicare Upcoding," Journal of Health Economics (March, 2004).

Smith, James, "Unraveling the SES-Health Connection," mimeo, RAND Corporation (September 2003).

Smolensky, Eugene, Leanna Stiefel, Maria Schmundt, and Robert Plotnick, "In-Kind Transfers and the Size Distribution of Income," in M. Moon and E. Smolensky (eds.) Improving Measures of Economic Well-Being. New York: Academic Press (1977).

U.S. Census, 65+ In the United States. Current Population Reports, Special Studies P23190 (1996).

van Doorslaer, E., et. al., 'Income-Related Inequalities in Health: Some International Comparisons," Journal of Health Economics 16 (1997): 92-112.

Wagstaff, Adam, Eddy van Doorslaer, and Pierella Paci, "On The Measurement of Horizontal Inequity in the Delivery of Health Care," Journal of Health Economics 10 (1991): 169-205.

Wagstaff, Adam, and Eddy van Doorslaer, "Overall versus Socioeconomic Health Inequality: A Measurement Framework and Two Empirical Examples," Health Economics 13 (2004): 297-301.

Walter, Louise C., Natalie P. Davidowitz, Paul A. Heineken, and Kenneth E. Covinsky, "Pitfalls of Converting Practice Guidelines into Quality Measures: Lessons Learned From a VA Performance Measure,” JAMA 291 (20) (May 26, 2004): 2466-2470.

Wennberg, John E., and Megan M. Cooper, The Dartmouth Atlas of Health Care. Chicago: American Hospital Association (1999).

Wennberg, John E., Jonathan Skinner, and Elliott Fisher, "Geography and the Debate Over Medicare Reform," Health Affairs (February 2002). 
Table 1: Medicare Expenditures by Year and Zip Code Income Decile

\begin{tabular}{|c|c|c|c|c|c|}
\hline & Decile 1 & Decile 3 & Decile 5 & Decile 8 & Decile 10 \\
\hline 1987 & 3346 & 3159 & 3228 & 3478 & 3588 \\
\hline 1988 & 3548 & 3309 & 3343 & 3556 & 3656 \\
\hline 1989 & 3926 & 3619 & 3590 & 3817 & 3980 \\
\hline 1990 & 4068 & 3637 & 3698 & 3904 & 3970 \\
\hline 1991 & 4265 & 3852 & 3811 & 4050 & 4022 \\
\hline 1992 & 4457 & 4039 & 3914 & 4119 & 4123 \\
\hline 1993 & 4740 & 4140 & 4102 & 4199 & 4219 \\
\hline 1994 & 5365 & 4553 & 4465 & 4432 & 4464 \\
\hline 1995 & 5743 & 4736 & 4702 & 4605 & 4611 \\
\hline 1996 & 5998 & 4931 & 4804 & 4596 & 4675 \\
\hline 1997 & 6120 & 5073 & 4778 & 4651 & 4666 \\
\hline 1998 & 6337 & 5311 & 5031 & 4804 & 4908 \\
\hline 1999 & 6153 & 5299 & 5002 & 4719 & 4946 \\
\hline 2000 & 5895 & 5068 & 4885 & 4614 & 4725 \\
\hline 2001 & 5970 & 5080 & 4873 & 4574 & 4802 \\
\hline $\begin{array}{c}\text { Dollar Change, } \\
1987-2001\end{array}$ & 2624 & 1921 & 1645 & 1096 & 1214 \\
\hline $\begin{array}{c}\text { Percentage Change, } \\
1987-2001\end{array}$ & 78.4 & 60.8 & 51.0 & 31.5 & 33.8 \\
\hline Source Med & & & & \\
\hline
\end{tabular}

Source: Medicare Continuous History Survey. Controls for age and sex. All expenditures expressed in $\$ 2001$. 
Table 2: 10-Year Survival Probabilities

By Age and Sex: 1982-91 and 1992-2001

\begin{tabular}{|c|c|c|c|c|c|c|c|c|}
\hline \multirow{3}{*}{$\begin{array}{l}\text { Income } \\
\text { Decile }\end{array}$} & \multicolumn{2}{|c|}{ Male } & \multicolumn{2}{|c|}{ Female } & \multicolumn{2}{|c|}{ Male } & \multicolumn{2}{|c|}{ Female } \\
\hline & \multicolumn{4}{|c|}{ Age 65-69 } & \multicolumn{4}{|c|}{ Age $75-79$} \\
\hline & $82-91$ & 92-01 & $82-91$ & $92-01$ & $82-91$ & 92-01 & $82-91$ & $92-01$ \\
\hline 1 & 59.0 & 61.9 & 75.8 & 75.4 & 34.6 & 35.1 & 51.2 & 51.8 \\
\hline 2 & 61.5 & 64.3 & 77.5 & 77.4 & 35.3 & 36.5 & 53.3 & 53.1 \\
\hline 3 & 62.0 & 66.0 & 77.8 & 78.7 & 35.0 & 37.6 & 53.6 & 54.1 \\
\hline 4 & 63.2 & 67.2 & 79.2 & 79.2 & 34.8 & 37.6 & 53.8 & 55.0 \\
\hline 5 & 64.1 & 68.2 & 77.9 & 79.4 & 36.0 & 39.7 & 53.9 & 55.1 \\
\hline 6 & 64.5 & 68.9 & 78.8 & 79.8 & 36.1 & 39.8 & 53.9 & 54.8 \\
\hline 7 & 64.6 & 69.7 & 79.0 & 80.4 & 35.4 & 39.9 & 53.8 & 55.7 \\
\hline 8 & 65.8 & 70.9 & 79.4 & 80.7 & 37.3 & 41.0 & 54.1 & 56.2 \\
\hline 9 & 66.5 & 72.5 & 79.8 & 81.8 & 38.2 & 42.9 & 54.1 & 56.3 \\
\hline 10 & 69.2 & 74.8 & 81.1 & 83.4 & 38.7 & 44.8 & 54.7 & 57.1 \\
\hline Sample & 188,177 & 217,272 & 229,308 & 263,093 & 98,053 & 126,011 & 152,606 & 187,554 \\
\hline
\end{tabular}


Table 3: Mammography Rates by Year and Zip Code Income Decile For Women Age 65-69

\begin{tabular}{|c|c|c|c|c|c|}
\hline & Decile 1 & Decile 3 & Decile 5 & Decile 8 & Decile 10 \\
\hline 1993 & 20.7 & 25.9 & 28.2 & 30.6 & 34.6 \\
\hline 1994 & 22.8 & 28.3 & 30.1 & 32.2 & 35.7 \\
\hline 1995 & 24.0 & 30.1 & 31.7 & 33.0 & 36.8 \\
\hline 1996 & 23.8 & 29.0 & 30.0 & 32.4 & 36.1 \\
\hline 1997 & 24.7 & 29.3 & 31.6 & 33.3 & 37.1 \\
\hline 1998 & $\begin{array}{c}32.0 \\
{[34.8]}\end{array}$ & $\begin{array}{c}39.5 \\
{[42.0]}\end{array}$ & $\begin{array}{c}41.0 \\
{[43.9]}\end{array}$ & $\begin{array}{c}43.5 \\
{[45.7]}\end{array}$ & $\begin{array}{c}46.7 \\
{[48.5]}\end{array}$ \\
\hline 1999 & $\begin{array}{c}34.3 \\
{[36.8]}\end{array}$ & $\begin{array}{c}41.9 \\
{[44.2]}\end{array}$ & $\begin{array}{c}43.6 \\
{[45.8]}\end{array}$ & $\begin{array}{c}45.4 \\
{[47.5]}\end{array}$ & $\begin{array}{c}48.1 \\
{[49.8]}\end{array}$ \\
\hline 2000 & $\begin{array}{c}34.6 \\
{[36.9]}\end{array}$ & $\begin{array}{c}42.6 \\
{[44.8]}\end{array}$ & $\begin{array}{c}44.7 \\
{[46.6]}\end{array}$ & $\begin{array}{c}45.9 \\
{[47.8]}\end{array}$ & $\begin{array}{c}48.3 \\
{[49.9]}\end{array}$ \\
\hline 2001 & $\begin{array}{c}36.5 \\
{[38.5]}\end{array}$ & $\begin{array}{c}44.0 \\
{[45.9]}\end{array}$ & $\begin{array}{c}45.3 \\
{[47.0]}\end{array}$ & $\begin{array}{c}47.0 \\
{[48.5]}\end{array}$ & $\begin{array}{c}49.4 \\
{[50.7]}\end{array}$ \\
\hline $\begin{array}{l}\text { Change: } \\
\text { 1993-2001 }\end{array}$ & 15.8 & 18.1 & 17.0 & 16.4 & 14.8 \\
\hline $\begin{array}{c}\text { Change: } \\
\text { 1997-2001 }\end{array}$ & 11.7 & 14.7 & 13.7 & 13.7 & 12.3 \\
\hline
\end{tabular}

Source: Medicare Part B Claims Data only. Figures in brackets are both Medicare Part B plus outpatient claims. 
Table 4: Rates of Effective Care for Acute Myocardial Infarction 1994/95: by Income Decile

\begin{tabular}{|c|c|c|c|c|}
\hline $\begin{array}{l}\text { Zip Code } \\
\text { Income } \\
\text { Decile }\end{array}$ & $\begin{array}{l}\text { Beta Blocker } \\
\text { Use at } \\
\text { Discharge* }\end{array}$ & $\begin{array}{c}\text { Ace } \\
\text { Inhibitor At } \\
\text { Discharge** }\end{array}$ & $\begin{array}{l}\text { Reperfusion } \\
\text { within } 12 \\
\text { Hours }\end{array}$ & $\begin{array}{l}\text { Smoking } \\
\text { advice } \\
\text { given } * * *\end{array}$ \\
\hline 1 & 40 & 57 & 32 & 33 \\
\hline 2 & 39 & 57 & 32 & 35 \\
\hline 3 & 43 & 60 & 33 & 34 \\
\hline 4 & 45 & 59 & 33 & 35 \\
\hline 5 & 45 & 59 & 34 & 37 \\
\hline 6 & 44 & 57 & 35 & 34 \\
\hline 7 & 45 & 59 & 37 & 34 \\
\hline 8 & 47 & 59 & 37 & 37 \\
\hline 9 & 45 & 59 & 36 & 35 \\
\hline 10 & 47 & 59 & 37 & 35 \\
\hline $\begin{array}{l}\text { Approx. } \\
95 \% \text { Conf. } \\
\text { Interval }\end{array}$ & \pm 1.4 & \pm 2.2 & \pm 1.7 & \pm 2.3 \\
\hline Sample size & 50,156 & 19,286 & 32,097 & 17,151 \\
\hline \multicolumn{5}{|c|}{$\begin{array}{l}\text { Source: Cooperative Cardiovascular Project. } \\
* \quad \text { Universe: appropriate (beta blocker) or eligible (for reperfusion). } \\
* * \quad \text { Universe: ideal patients } \\
* * * \quad \text { Universe: smokers }\end{array}$} \\
\hline
\end{tabular}


Figure 1: Medicare Expenditures by Income Decile, 1987-2001

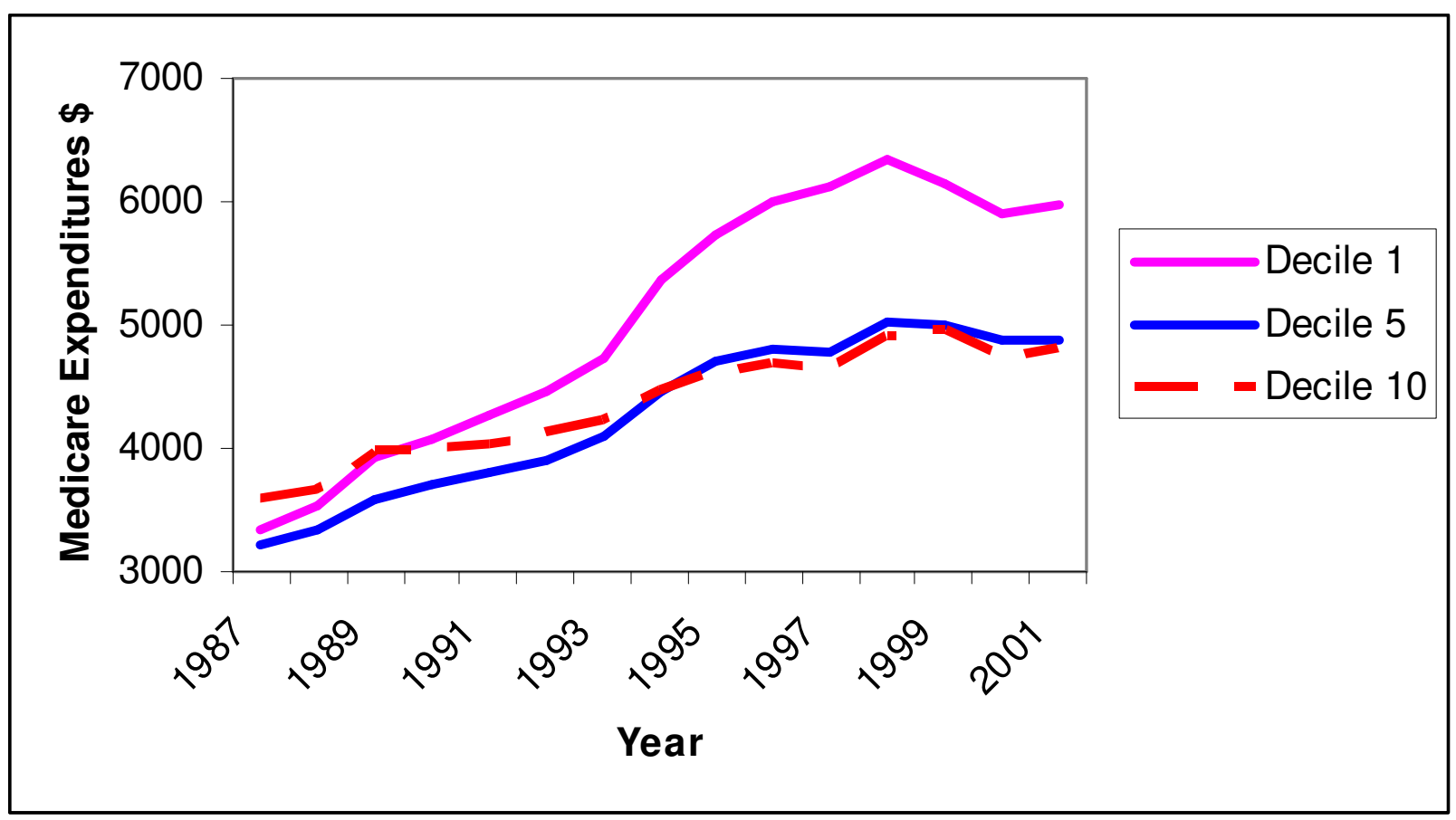


Figure 2: Home Health Care Expenditures by Income Decile, 1987-2001 Age 80+

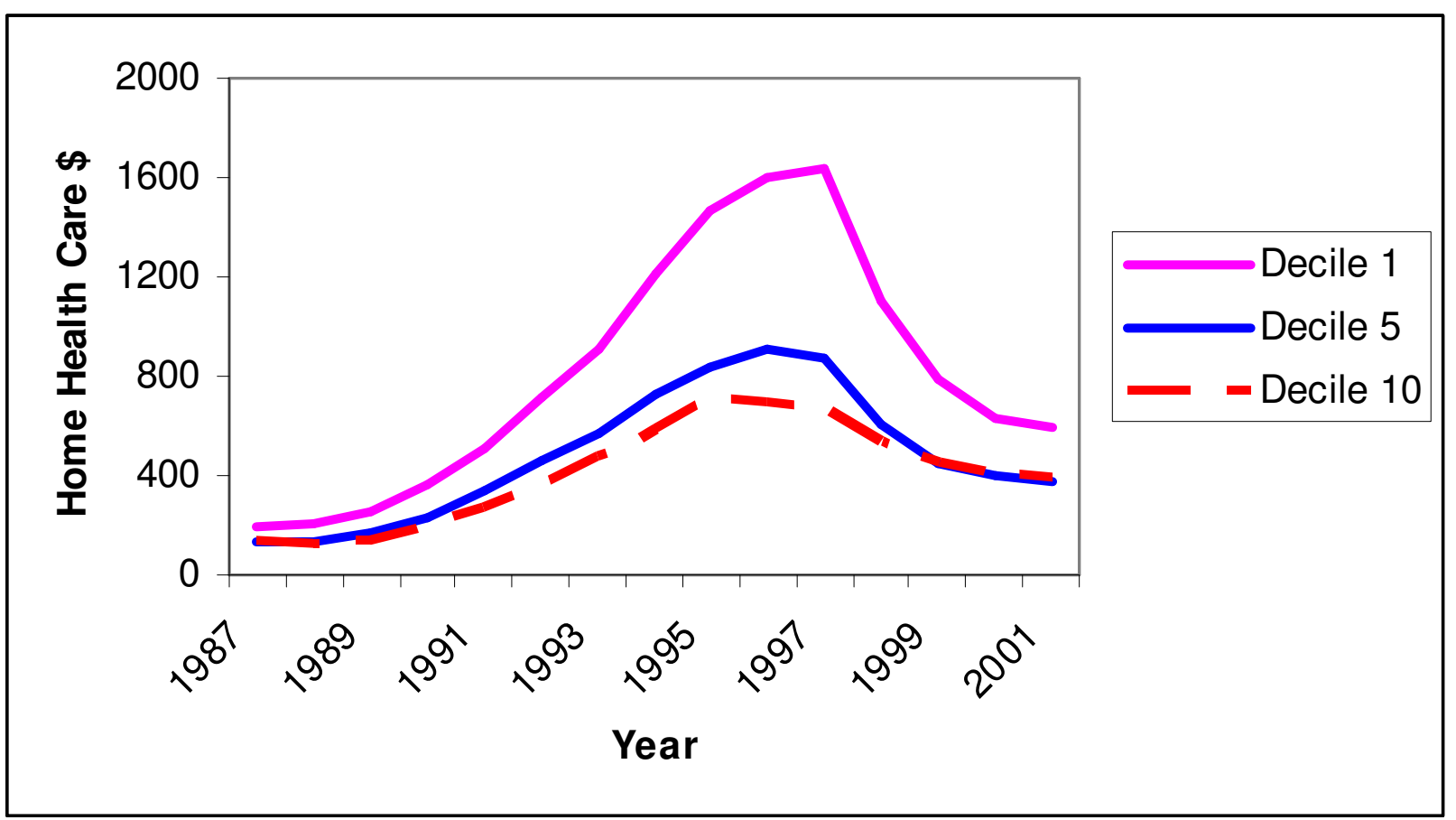


Figure 3: 10-Year Survival Rates For Age 65-69 Cohorts By Sex: 1982-91 and 1992-2001

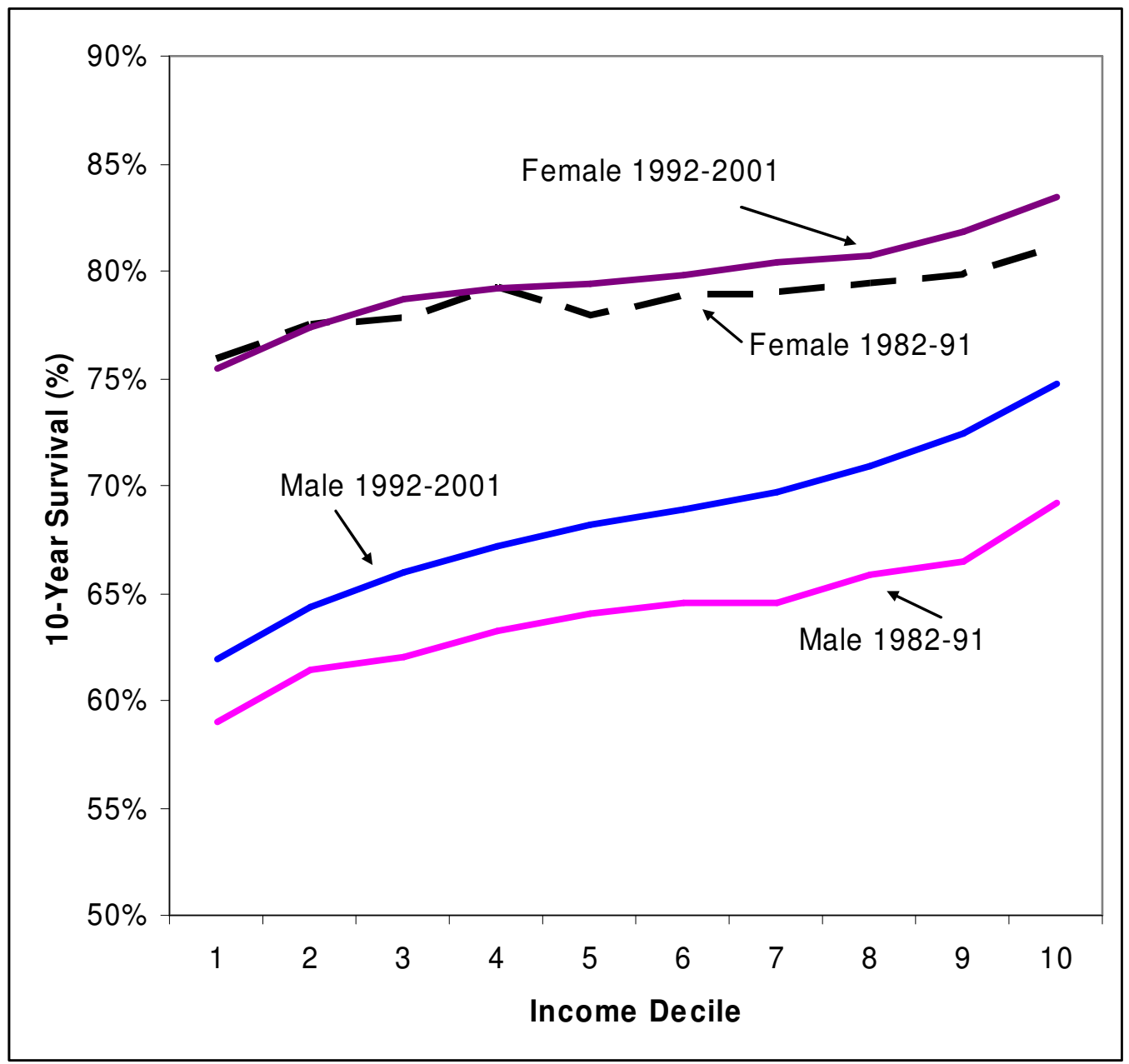


Figure 4: Change in Mammography Rates 1993-2001 By Zip Code Income Decile

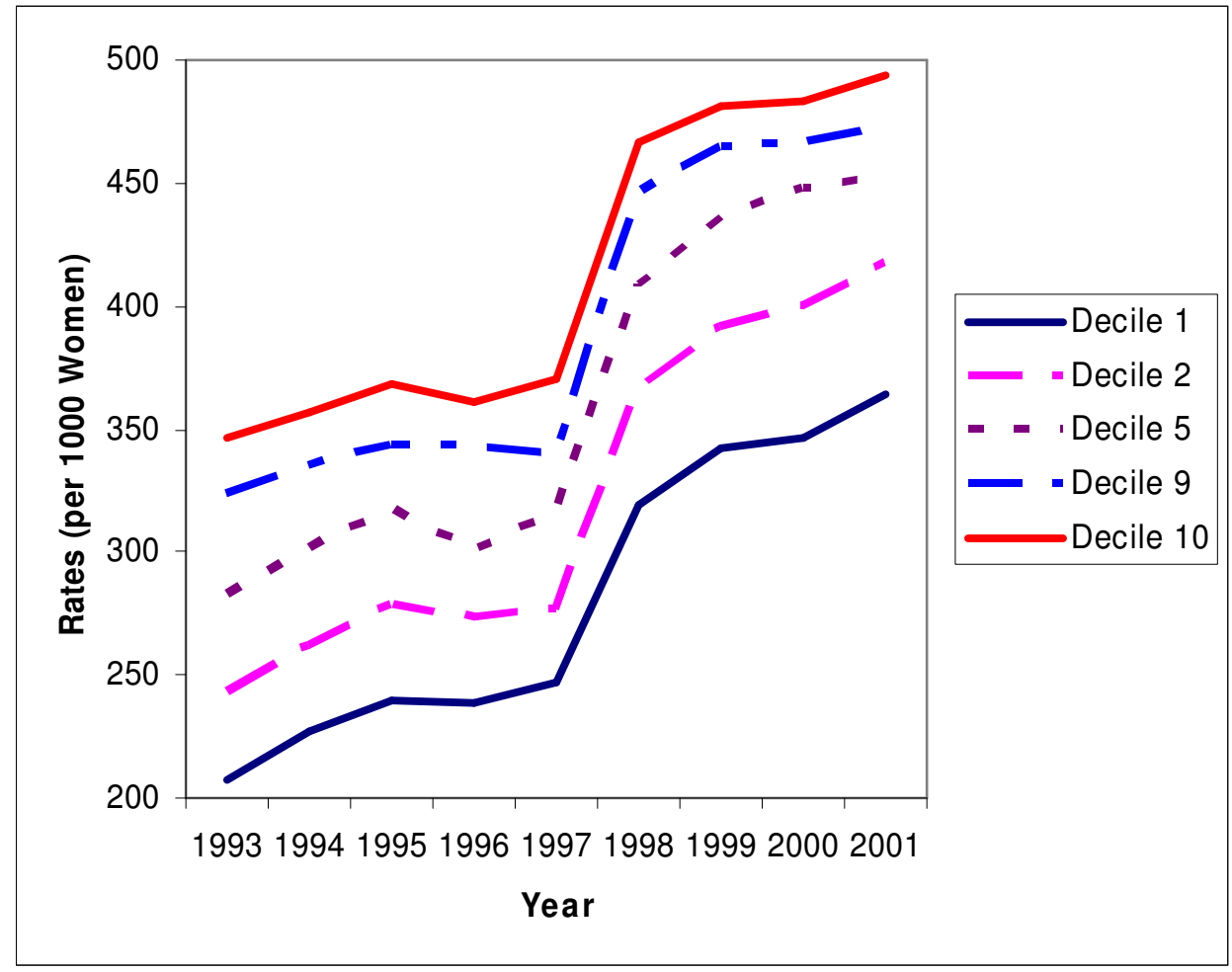

Note: Rates per Females Age 65-69. The 100 dollar coinsurance rate was removed on 1 January 1998. 
Figure 5: Estimates of the Income Gradient for the Use of $\beta$ Blockers for Ideal Patients: With and Without State-Level Controls, 1994/95

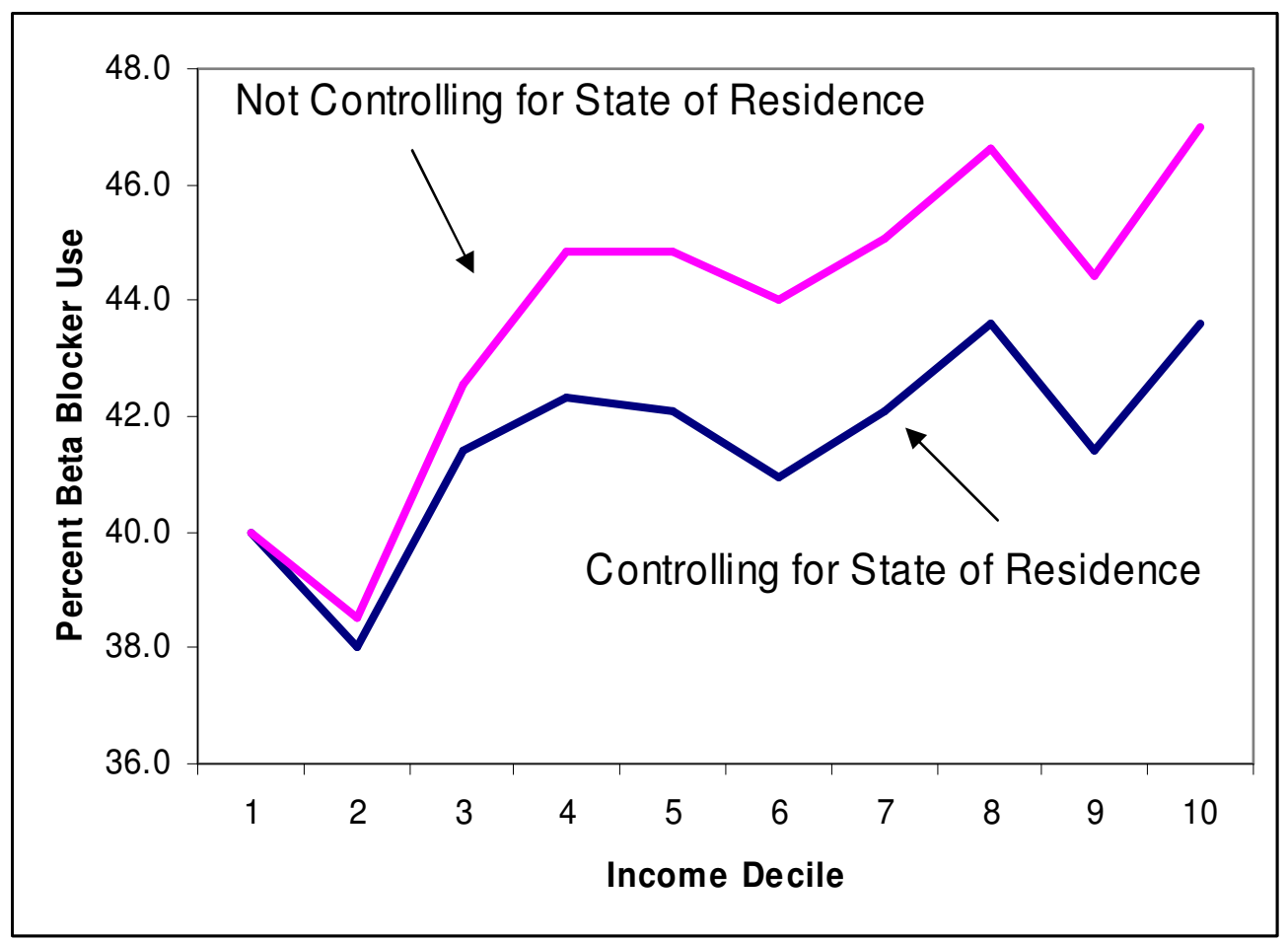

